\title{
Outros espaços nas artes visuais
}

\author{
Ricardo Nascimento Fabbrini a (D)
}

\section{RESUMO}

O artigo caracteriza, inicialmente, a concepção de temporalidade que vigorou no imaginário das vanguardas artísticas dos anos 1910 aos anos 1930: a ideia de um tempo linear, sucessivo, cumulativo, homogêneo e "vazio", porque para ser conquistado. Foi essa concepção de tempo prospectivo, teleológico, no qual o télos é a Utopia, que orientou as vanguardas construtivas até a Segunda Guerra Mundial. Depois do Holocausto (ou das bombas de Hiroxima e Nagasaki), as ideias de progresso, ou de aperfeiçoamento, próprias dessa concepção prospectiva do tempo, ruíram. O futuro deixou de ser considerado o reino da esperança, da projeção do desejo, para tornar-se sombrio ou ameaçador. Desde então, vigora no imaginário artístico-cultural a noção de distopia, ou utopia negativa, entendida como a figuração de uma sociedade opressiva projetada no futuro próximo ou distante, à qual se chegará se não forem alterados os rumos da história. É o que verificamos nas obras visuais do artista alemão Harun Farocki, do chinês Ai Weiwei e do espanhol Antoni Muntadas, realizadas nas três últimas décadas, nas quais a distopia é figurada como sociedade de controle. Por fim, acentuamos que diversos críticos de arte vêm mobilizando, desde os anos 1990, a noção de heterotopia de Michel Foucault para caracterizar o poder de negatividade de certa arte contemporânea. Recordamos que as heterotopias (diferentemente

Recebido em: 21/12/2020 Aceito em: 26/02/2021

\footnotetext{
a Universidade de São Paulo, Faculdade de Filosofia, Letras e Ciências Humanas, Departamento de Filosofia, São Paulo, SP, Brasil. E-mail: ricardofabbrini@uol.com.br
} 
das utopias e distopias) são, para o autor, "contraposicionamentos em lugares reais", "lugares efetivos", ou seja, lugares que, em aparente paradoxo, "estão fora de todos os lugares, embora sejam efetivamente localizáveis" no mundo existente, como ocorre, a nosso ver, nas instalações do artista argentino Rirkrit Tiravanija (que, por sua vez, remontam às proposições construtivas de Lygia Clark e Hélio Oiticica).

Palavras-chave: Arte Contemporânea. Utopia. Distopia. Heterotopias. Resistência.

O imaginário dos artistas de vanguarda do início do século XX operava com uma noção de tempo cindido, no qual um presente fugaz, desprovido de um passado regulador, mira um futuro sempre inalcançável. Nesta época, a concepção de temporalidade, oriunda da esfera da técnica e da ciência, colonizou a esfera da arte e da cultura, de modo que os artistas vanguardistas partilharam com os cientistas a crença nas ideias de progresso - do latim pro-gredior: "andar gradualmente para frente". Prevaleceu, assim, no imaginário destas vanguardas históricas, dos anos 1910 aos 1930, uma perspectiva análoga à da concepção positivista da ciência: a ideia de um tempo linear, sucessivo, cumulativo, homogêneo e "vazio", porque para ser conquistado. Foi essa concepção de tempo prospectivo, teleológico, no qual o télos é a Utopia, consolidada nos manifestos artísticos, que orientou a prática dessas vanguardas.

Artistas como os futuristas italianos nos anos 1910 e os construtivistas russos nos anos 1920, apesar de assumirem posições distintas no plano político-ideológico, haja vista que os primeiros se aproximaram do fascismo, enquanto os últimos visavam à construção do socialismo, apostaram, igualmente, nos poderes transformadores da arte. Herdeiros da tradição romântica, esses artistas atribuíram à arte de vanguarda uma importante e nobre função, a saber: a de promover a construção de uma "sociedade ideal", inteiramente outra (uma alteridade radical). A forma artística, seja a arquitetura, o design seja a pintura, atuaria, segundo esses artistas, de tal modo sobre 
o corpo sensório-motor do homem comum, que este sairia transformado da experiência estética. Se é verdade que a arte não tem o poder de transformar diretamente o mundo, ela poderia, no entanto, - como dizia Herbert Marcuse (1986) atuar sobre o fruidor, que, sendo modificado pela experiência estética, alteraria a sua maneira de se relacionar com os demais homens, de tal sorte que, ao fim e ao cabo, teríamos a transformação da totalidade da sociedade. Isto porque a experiência do observador, vivida na fruição da obra de arte, ficaria de tal maneira retida em sua memória afetiva que ele desejaria vê-la estendida a todos os outros momentos de sua vida. $O$ fruidor perceberia, assim, a distância que existe entre a felicidade vivida na fruição artística e a realidade existente que a interdita.

Ou seja: segundo o imaginário utópico-revolucionário das vanguardas históricas, a forma artística poderia atuar sobre as faculdades subjetivas do observador (como a sensibilidade, a imaginação e o entendimento), propiciando-lhe uma experiência sui generis porque sem contrapartida no ramerrão cinzento da vida cotidiana. Essa experiência transformadora, vivida na fruição artística, já foi caracterizada como um jogo livre entre as faculdades do sujeito; entre o "impulso sensível" (a sensibilidade) e o "impulso formal" (o entendimento), nas Cartas sobre a educação estética do homem, de 1794, de Friedrich Schiller (1990), que alcançou - com as devidas mediações - o imaginário das vanguardas artísticas.

$\mathrm{Na}$ fruição da arte de vanguarda (seja obra artística seja poética do gesto) teríamos, assim, uma experiência de eliminação das hierarquias: tanto do poder cognitivo, que determina os dados sensíveis segundo as categorias do entendimento, quanto do poder da sensibilidade, que impõe seus objetos, isto é, sua "passividade sensível" (SCHILLER, 1990, p. 76). Essa "ação recíproca entre os impulsos, em que a eficácia de cada um ao mesmo tempo funda e limita a do outro"; ou seja, em que "cada impulso encontra sua máxima manifestação justamente pelo fato de que o outro é ativo", seria vivido pelo fruidor como uma experiência de liberdade (SCHILLER, 1990, p. 71; 77). Desse "grau zero das faculdades", na expressão de Schiller (1990, p. 110), que corresponde à "esfera lúdica", na qual o homem estaria momentaneamente livre de toda relação de dominação, resultariam "novas configurações do sensível." 
Essa crença de que a fruição artística pode ser uma experiência de emancipação - que fora denominada no século XIX de "promessa de felicidade" (promesse de bonheur) por Stendhal e Baudelaire - orientou, portanto, o projeto moderno que foi capitaneado pela arquitetura racionalista ou funcionalista até o advento da Segunda Guerra Mundial. Segundo a "Ideologia do Plano", caberia à arquitetura moderna estetizar a totalidade das exteriorizações da vida social, realizando a ideia romântica de obra de arte total (Gesantkunstwerke). Essa função transformadora do mundo foi atribuída, sobretudo, à arquitetura - tomada aqui em sentido amplo porque abarcando o design e o urbanismo -, não apenas porque nela se realizaria o ideal da confluência das artes, mas também porque, em virtude de sua própria materialidade, ela condicionaria o modus vivendi do homem comum na Nova Cidade.

Nesse estado de síntese das artes, ou de obra de arte total, aqui equiparados, não haveria mais diferenças intrínsecas entre ser e criar, existir e produzir. Neste novo mundo no qual a arquitetura e os objetos utilitários seriam, ao mesmo tempo, belos e úteis, vigoraria no homem uma harmonia entre suas disposições anímicas. Em síntese: o projeto moderno de extração romântica, encampado pela arquitetura racionalista ou funcionalista, constituiria uma nova espécie de ser - um "homem pleno" nos termos dos manifestos, Neoplasticismo, de Piet Mondrian, de 1917 (2008), e Suprematismo, de Kasimir Maliévitch, de 1919 (1975) - na medida em que concedia à "existência humana" sua "liberdade essencial" (SCHILLER, 1990, p. 83)

A Utopia, ou Cidade Ideal, adquiria, assim, um desenho (um design) na prancheta do arquiteto moderno. Pensando a cidade como síntese das artes, segundo o ideário funcionalista, Le Corbusier (1989, p.135) prescreveu no tópico 92 da Carta de Atenas, publicada apenas em 1941: "A arquitetura é a chave de tudo". Sua Cidade Radiosa (Ville Radieuse), de 1931, seria composta de quatro setores integrados que atenderiam às necessidades básicas de seus habitantes: "assegurar aos homens moradias saudáveis" (Habitar); "sanear seus locais de trabalho" (Trabalhar); e prever "a boa utilização das horas livres" (Recrear-se), o que só seria possível mediante uma "rede circulatória" que "assegurasse as trocas" entre estes três setores 
(Circular) (LE CORBUSIER, 1989, p. 77). Essa Cidade Radiosa, assim como o anterior Plain Voisin, de 1925, para uma cidade de três milhões de habitantes, inscreveu a arquitetura moderna (e o arquiteto enquanto urbanista-demiurgo) na história de longa duração da Utopia (ou Cidade Ideal) que remonta à própria origem da filosofia ocidental: à República (ou Politeía) de Platão, no séc. IV a.C.

É possível estabelecer uma analogia entre a Cidade Radiosa e a República (Kalè pólis) de Platão (1983), levando-se em consideração, inclusive, as referências de Le Corbusier ao mundo grego. A Bela Pólis desenhada pela imaginação de Sócrates e seus interlocutores, mas por meio do método dialético, seria uma Cidade fundada numa estrutura social piramidal, na qual a classe econômica (agricultores, comerciantes e artesãos) ocuparia a base da pirâmide; os guardiões ou guerreiros (a classe militar) ocupariam o seu centro; e, por fim, os magistrados ou governantes (ou seja, os filósofos), responsáveis pela manutenção desta estrutura estamental, estariam em seu cume. Platão não apenas descreve, vale notar, como haveria de ser a Cidade Ideal, mas também indica - diferentemente de outros utopistas - o meio mais adequado para construí-la. Competiria ao Estado, mediante um longo processo educacional, desenvolver as aptidões naturais de cada um dos membros dessa comunidade, desde a infância, visando a determinar-lhes, após sucessivas avaliações de produtividade, a posição que cada um deveria ocupar no interior dessa estrutura social. Essa cidade seria harmoniosa, em outros termos, porque a cada cidadão seria destinada a função (ou atividade laboral) para a qual, por natureza (phýsis), ele estaria mais apto a desempenhar. A Cidade Ideal (ou Cidade Justa) seria aquela na qual os filósofos governam, os militares defendem e os membros da classe produtiva proveem a sociedade com todos os recursos necessários para a sua conservação (PLATÃO, A República, Livro IV, 1983, p. 161-208).

A Cidade Radiosa de Le Corbusier assim como a República platônica são cidades tecnocráticas, pois fundamentam a ordem social na especialização das funções (tékhnai). No tópico 15 da Carta de Atenas, Le Corbusier afirma, analogamente, que "o zoneamento é a operação feita pelo plano de cidade com o objetivo de atribuir a cada função e a cada indivíduo seu justo lugar." (LE CORBUSIER, 1989, p. 58). Os dois modelos 
compartilham, além disso, o pressuposto segundo o qual uma Cidade só será harmoniosa se seus cidadãos também desenvolverem uma harmonia interior. Segundo Platão, para que haja o equilíbrio entre as três classes que compõem a República é preciso que, nos membros de cada uma delas, prevaleça uma dada disposição anímica. Se a alma (psyché) de todos os homens é composta por uma faculdade racional (lógos), passional (páthos) e apetitiva (hýbris), em diferentes proporções, pode-se concluir que na alma dos agricultores o apetite deve predominar sobre a paixão e a razão; na alma de um guerreiro a paixão (como a coragem) há de prevalecer sobre o apetite e a razão; e, por fim, na alma dos governantes é o lógos que deve dominar as disposições passional e apetitiva. A Cidade Ideal de Platão (1983) está baseada, assim, no paralelismo e na interdependência entre três esferas: o homem (a alma), a cidade (a cultura) e a natureza (o cosmos).

De modo semelhante, a Cidade Radiosa de Le Corbusier pressupõe uma correlação entre os quatro setores da cidade, enumerados acima, e as necessidades vitais de seus habitantes. Se o urbanismo tem quatro funções sendo a quarta delas, a "rede circulatória", ou o sistema de trocas entre as três anteriores, é porque Le Corbusier atribui ao homem, considerando-o sempre em abstrato (ou como um ser universal), três "atividades humanas naturais" a serem desempenhadas ao longo de um único dia (e de uma vida inteira): descansar em moradias saudáveis; trabalhar em locais igualmente salubres; e distrairse ou consumir nas "horas de lazer" (LE CORBUSIER, 1976, p. 165). Sem desconsiderar o fundamento humanista deste projeto que, recorrendo aos avanços técnicos do capitalismo industrial do início do século passado, visava a suprir as necessidades elementares de todo habitante de uma cidade moderna (como as de insolação e ventilação, em sua "unidade de habitação"), é inegável o seu caráter impositivo, senão prescritivo. Le Corbusier não se limitou a descrever a Cidade Radiosa, cuja organização deveria ser análoga à das fábricas ou das empresas, mas, mediante "sábias previsões", procurou até mesmo antecipar o seu futuro; afinal, no projeto racional de uma cidade moderna nada deveria ser deixado ao imprevisto ou à contingência: "o acaso deve ceder diante da previsão, e o programa deve suceder à improvisação." (LE CORBUSIER, 1989, p. 77). 
Le Corbusier visava, portanto, a legislar sobre algo ingovernável, a saber: a imponderabilidade do devir. Esse projeto moderno, em outros termos, conduzido pela arquitetura - "Arquitetura ou revolução" alertava Le Corbusier (1981), em Por uma arquitetura, de 1923 -, que visava a estetizar a vida, mostrou-se no curso do tempo mais que totalizante, "totalitário", haja vista que ele prescrevia como se haveria de viver, do alvorecer ao anoitecer. Foram diversas as críticas, principalmente após a Segunda Guerra, ao caráter universalista e idealizador de seu "programa" que teria feito tábula rasa das condições materiais de vida, tanto geográficas quanto culturais, de cada comunidade, considerada em sua singularidade.

Destaque-se entre essas críticas, a oposição sistemática ao urbanismo de Le Corbusier pela Internacional Situacionista, de 1958 a 1972. Guy Debord (2003, p.136) afirmava no número 6 da publicação IS (Internacional Situacionista), em 1961, que "os discursos sobre urbanismo são mentiras tão evidentes quanto o espaço organizado pelo urbanismo" (moderno) - que culminou na construção de Brasília: "o microcosmo da Weltanschauung (concepção de mundo) burocrática" - é "o próprio espaço da mentira social e da exploração reforçada." Portanto, aqueles que alardeiam "o poder do urbanismo" tentariam, na realidade, ocultar que estão a serviço do "urbanismo do poder." (DEBORD, 2003, p. 137). O "urbanismo unitário", pedra de toque do movimento situacionista, não deveria constituir-se, assim, como doutrina, asseverava Debord, mas como crítica ao urbanismo moderno, sobretudo à separação das funções em zonas urbanas defendidas por Le Corbusier na Carta de Atenas, como vimos. Portanto, não seria concebível um modelo de Cidade Situacionista, mas um "uso situacionista da cidade" existente, que, acolhendo a mutabilidade do mundo da vida, ou seja, o que há nela de contingência ou imprevisão favoreceria a "realização de uma vida mais rica e completa." (JACQUES, 2003, p. 105).

Essa crítica dos situacionistas ao caráter utópico do projeto moderno de viés funcionalista de fundar uma Cidade Ideal com base em um grau zero, ou seja, ignorando as condições materiais ou histórico-culturais dos diferentes Estados Nacionais, disseminou-se após a Segunda Guerra Mundial. Desde então, houve uma alteração profunda na concepção de temporalidade, uma vez que o futuro deixou de 
ser o reino da esperança, da projeção do desejo, senão da utopia, no sentido das vanguardas da primeira metade do século passado, para tornar-se sombrio ou ameaçador. Passou-se, então, a viver, na expressão de Octávio Paz (1986) em "tempos nublados". É o período da Guerra Fria, da oposição leste-oeste, da corrida armamentista e da ameaça de destruição nuclear do planeta. Depois das bombas de Hiroxima e Nagasaki, as ideias de progresso, de aperfeiçoamento, próprias da concepção prospectiva do tempo, à qual nos referimos acima, ruíram. Acentuou-se, assim, o quadro já indiciado no período entre guerras - caracterizado pela ascensão dos totalitarismos nazifascistas - de "eclipse da razão", na expressão de Max Horkheimer (1976), da "Teoria Crítica" da Escola de Frankfurt.

Esse abandono da concepção teleológica do tempo pressuposto da noção de utopia - foi entendido por Horkheimer (1976, p. 21) como o resultado de um desequilíbrio produzido no curso da história entre as duas dimensões que constituem a razão. Sua "dimensão técnica ou instrumental" teria prevalecido sobre o "conteúdo objetivo da razão." A razão técnica é, segundo Horkheimer, a razão utilitária, pragmática, relativista, que relaciona os meios aos fins. Do ponto de vista dessa razão formalizada, voltada para a operacionalidade, "uma atividade só será considerada racional quando servir a outro propósito." (HORKHEIMER, 1976, p. 75). Essa face da razão, que triunfou historicamente, não visaria, portanto, a compreender as relações entre o homem e a natureza, ou dos homens entre si, uma vez que ela toma a natureza como uma exterioridade a ser manipulada ou dominada, ou seja, na perspectiva da razão instrumental "o que importa não é aquela satisfação que os homens chamam de verdade; mas o proceder eficaz." (HORKHEIMER, 1976, p. 31).

A perda do horizonte de emancipação teria resultado, assim, da repressão da "razão objetiva", socrático-platônica, que busca a compreensão da "estrutura do real." (HORKHEIMER, 1976, p. 55). Esta é a face da razão (vencida no curso da história) que visa a harmonizar o homem consigo próprio, os homens entre si na esfera política e os homens com a natureza. Da perspectiva desta "razão cognitiva" a natureza não é, portanto, algo exterior, um objeto de exploração ou de dominação total e contínua, na medida em que o homem é parte da natureza. De modo que ao reprimi-la, ele se reprime; ao subjugá-la, ele 
${ }^{1}$ Esta hegemonia das distopias (em relação às utopias) no imaginário artístico-cultural após a Segunda Guerra Mundial, e, particularmente, na dita pós-modernidade (a partir do fim dos anos 1970) é nítida, como se sabe, no cinema. Destaque-se aqui, como marco inaugural de uma filmografia sobre sociedades sombrias, o filme de ficção científica Blade runner: o caçador de androides (1980), de Ridley Scott, baseado no romance Androides sonham ovelhas elétricas? (1968), de Phillip K. Dick, que ensejou acalorado debate na década de 1980. Essa hegemonia permanece no século XXI, não apenas no cinema, mas também no gênero literário de ficção-científica, como atesta, entre tantos sintomas, o interesse do leitor atual, no Brasil, pelas descrições de "utopias negativas", seja em romances do século passado, que só agora foram traduzidos no país, como Nós (1924) de Yevgeny Zamyatin, seja em romances que recentemente ganharam novas traduções, como $O$ admirável mundo novo (1935), de Aldous Huxley; Fahrenheit 451 (1953) de Ray Bradbury; e $O$ senhor das moscas (1954), de Willian Goldin, entre outros. Por fim, esse predomínio das distopias no imaginário sobre as sociedades do futuro se acentuou ainda mais, neste ano de 2020, em função do isolamento social decorrentes das medidas sanitaristas de combate à pandemia do novo Coronavírus. Neste cenário marcado pelo medo ao contágio pela Covid-19, em meio a uma recessão econômica global, se subjuga - como mostraram as análises de "psicologia das massas", de Sigmund Freud, Wilhelm Reich, Elias Canetti, e, como estamos vendo, de Theodor Adorno (1985) e Max Horkheimer (1976).

O predomínio da razão instrumental sobre a razão objetiva acarretou, em síntese, a perda do poder prescritivo, normativo-teleológico da razão orientada para a emancipação. As ideias de justiça social, de igualdade real ou de liberdade política, entre outras, deixaram de operar como ideias reguladoras para uma ação transformadora do mundo. As tragédias do século passado mostraram que a aposta cega nos poderes supostamente liberadores da razão técnica se reverteu, em grande medida, em seu contrário: na negação da vida (ou de Éros). Constatou-se que a autonomia crescente da razão tecnológica em relação ao "mundo da vida", ao tomar os meios técnicos como fins, acabou, entre outras consequências, por implicar a morte em larga escala, inicialmente nas trincheiras cruentas da Primeira Guerra Mundial, e, em seguida, nas câmaras de gás da Segunda Guerra. Evidenciou-se que, se o progresso técnico pode libertar afirmando a vida (Éros), ele também pode oprimir enquanto pulsão de morte (Thánatos).

O futuro tornou-se, assim, soturno: "O futuro já não é mais o depositário da perfeição, mas sim, do horror", dizia Octavio Paz (1984, p. 51). Desde então, no imaginário dos artistas (e do público) têm prevalecido as "utopias negativas" (na expressão de Adorno e Horkheimer) ou distopias (no termo cunhado pelo historiador Gregory Claeys, em 1740). Entendase, aqui, por "distopia", "utopia negativa", ou "antiutopia", a descrição imaginária de uma sociedade opressiva projetada no futuro próximo ou distante que não se deseja construir, mas à qual se chegará se não forem alterados os rumos da história. ${ }^{1}$ É preciso assinalar que a distopia, assim como a utopia propriamente dita (ou utopia positiva), exerce nítida função política, pois ela também opera criticamente em relação à realidade do presente. Se a utopia opera como ideia reguladora de uma sociedade ideal, a utopia negativa alerta para os riscos do que deve ser evitado. A distopia literária ou artística, segundo Jean Baudrillard (1991, p. 195-201), é uma estratégia discursiva que contrapõe o "niilismo irônico" (ou crítico) ao "niilismo da neutralização" próprio do sistema hegemônico. Seu "niilismo ativo da radicalidade" (assim como 
a maior desde o fim da Segunda Guerra Mundial, tornou-se usual - abolindo-se a distância entre o presente e o futuro - nomear a própria realidade no presente, de distópica. da própria filosofia de Baudrillard) seria o da "antecipação dramática" daquele que "leva até o limite do insuportável esse mesmo sistema" vigente; o que significa dizer que o que concede credibilidade ou verossimilhança à utopia negativa (ao desenho sombrio do futuro) é o fato de que seus traços já estão indiciados no presente, tais como o autoritarismo político, a desigualdade social, a vigilância tecnológica ou a crise ambiental. (BAUDRILLARD, 1991, p. 33). A violência simbólica da distopia seria, assim, "o recurso que atualmente nos resta", ainda que estejamos, segundo o autor, na "era das críticas sem consequência.". (BAUDRILLARD 1991, p. 201). Pode-se concluir - distanciando-nos, aqui, do fatalismo de Baudrillard (1991, p. 33) que sentencia em Simulacros e simulação: "Mas já é tarde demais!" - que as distopias alertam para o fato de que "a destruição, ainda que iminente, nunca é completa", mostrando que é preciso reagir aos "estratagemas apocalípticos." (DIDIHUBERMAN, 2011, p. 39).

Em suma: na sociedade controladora, administrada, "semibárbara e que tende para a barbárie", recuperando os termos atribuídos por Adorno e Horkheimer tanto aos totalitarismos europeus do entreguerras, quanto à democracia de massas norte-americana do pós-Segunda Guerra Mundial - diagnóstico que aqui estendemos à sociedade neoliberal resultante do desmonte do Estado de Bem-Estar Social (Welfare State) que, iniciado nos anos 1970, ainda está em curso sob o eufemismo de "políticas de austeridade econômica" - não é mais possível manter uma visão esperançosa em relação ao futuro. Por que haveria, assim, de se esperar que um dado artista contemporâneo, movido por uma espécie de voluntarismo anacrônico, restituísse à arte o poder que a todos o nosso tempo interdita, a saber: o de acenar para uma sociedade de homens livres no futuro? Como se verá, é na criação de distopias, tais como as caracterizamos acima, que diversos artistas visuais têm afiado o gume de suas críticas à sociedade do presente.h

Nas obras do artista alemão Harun Farocki, do chinês Ai Weiwei e do espanhol Antoni Muntadas, realizadas nas três últimas décadas, temos a figuração de distopias, caracterizadas como sociedades de controle. Em texto sobre a sociedade de controle, de 1990, Gilles Deleuze (1992) comentava as formas de opressão decorrentes da transição do capitalismo industrial, fabril ou fordista, para o capitalismo pós-industrial, acionário 
ou de serviços. Estávamos vivendo, desde os anos 1970, alertava Deleuze (1992, p. 223), não apenas uma evolução tecnológica, mas uma profunda mutação do capitalismo, uma vez que o capital não era mais dirigido à compra de matéria-prima e à venda de produtos acabados, mas à venda de serviços e à especulação financeira. E desta mutação teria resultado a "implantação progressiva e dispersa de um novo regime de dominação" que não se limitava mais aos mecanismos de controle da "sociedade disciplinar", como o confinamento físico dos indivíduos, na prisão, no hospital, na fábrica, na caserna ou na escola, tal como descrevera Michel Foucault em História da loucura na idade clássica, de 1972, ou Vigiar e Punir, de 1975, entre outros livros. (DELEUZE, 1992, p. 223).

Segundo esse diagnóstico de Deleuze, houve a substituição dos mecanismos de confinamento institucional da sociedade disciplinar, que pressupõe o poder centralizado de um Estado soberano, porque detentor do monopólio da coerção organizada, para novas estratégias disseminadas eimateriais de dominação, ainda que ocorra, muitas vezes, uma sobreposição entre essas estratégias repressivas, produzindo-se uma espécie de excedente punitivo. Nesta direção, Deleuze (1992, p. 215) ressaltava, em entrevista de 1990, que o próprio Foucault foi "um dos primeiros a dizer que as sociedades disciplinares são aquilo que estamos deixando para trás", ou seja, "o que não somos mais", porque estaríamos "entrando nas sociedades de controle, que não funcionam mais por confinamento, mas por controle contínuo e comunicação instantânea": "O que conta é que estamos no início de alguma coisa nova; ou seja, na aurora de novas formas de controle que precisariam ser descritas." (DELEUZE, 1990, p. 216).

Na síntese de Deleuze, "a fábrica cedeu lugar à empresa", como se pode constatar nos seguintes exemplos:

No regime das prisões: a busca de penas substitutivas, ao menos para a pequena delinquência, e a utilização de coleiras eletrônicas que obrigam o condenado a ficar em casa em certas horas. No regime das escolas: as formas de controle contínuo, avaliação contínua, e a ação da formação permanente sobre a escola, o abandono correspondente de qualquer pesquisa na Universidade, a introdução da empresa em todos os níveis de escolaridade; No regime dos hospitais: a nova medicina "sem médico nem doente", que resgata doentes potenciais e sujeitos a risco [antecipando os aplicativos desenvolvidos 
durante a pandemia da Covid-19, em 2020, destinados a localizar os portadores potenciais do vírus], que de modo algum demonstra um progresso em direção à individuação, como se diz, mas substitui o corpo individual ou numérico pela cifra [que possibilita o acesso de dado indivíduo a certa informação] de uma matéria dividual [divisível ou parcial] a ser controlada [uma vez que esta informação encontra-se armazenada em bancos de dados]. No regime de empresa: as novas maneiras de tratar o dinheiro, os produtos e os homens, que já não passam pela antiga forma-fábrica. São exemplos frágeis [- conclui Deleuze -], mas que permitiria compreender melhor o que se entende por crise das instituições, isto, é a implantação progressiva e dispersa de um novo regime de dominação. (DELEUZE, 1990, p. 224-255, grifo nosso).

Farocki mostram uma sociedade de controle na qual as imagens técnicas são mantidas como privativas dos aparelhos de Estado, das empresas privadas ou das plataformas digitais (as Big-Techs). Seus filmes, exibidos, em regra, como videoinstalações em galerias de arte, partem do registro de imagens colhidas por câmeras de segurança ou de "imagens operacionais" obtidas tão somente para uso interno de instituições, como o exército ou as prisões. As fontes primárias utilizadas por Farocki no filme Imagens do mundo e inscrições de guerra (Bilder der Welt und inschrift des Krieges), de 1988, são fotografias técnicas, desenhos, diagramas e gravações realizadas durante as próprias operações militares, com a finalidade de fiscalizar essas ações. No centro desse filme, composto por imagens operacionais, estão fotografias aéreas de Auschwitz obtidas em 1944, por meio de aviões de bombardeio norte-americanos, mas que se mantiveram esquecidas ou em segredo até 1977.

Em Imagens de prisão (Gefangnisbilder), de 2002, Farocki exibe, em apurada montagem, imagens do sistema de vigilância de presídios, que estavam condenadas ao desaparecimento, uma vez que nada nelas justificava sua preservação, na medida em que a coleta ininterrupta de imagens por uma câmera ostensiva, dia e noite, tem por função exclusiva a intimidação do prisioneiro (que perde toda privacidade) e o registro (em flagrante) de eventual ação ilícita, como uma tentativa de fuga. São imagens de controle sobre os corpos não apenas dos prisioneiros, mas também dos agentes penitenciários (para fins de treinamento e de fiscalização de sua atuação profissional): 
a abertura diária das celas; a disposição dos presos em filas indianas; sua revista pelos carcereiros; sua marcha regular até o pátio; seus movimentos circulares na hora de sol; e, até mesmo, seu trabalho nas oficinas do presídio. Em Imagens de prisão, Farocki dá a ver, em suma, por imagens operacionais, o exercício contínuo das "tecnologias de poder" que "definem como se pode ter domínio sobre o corpo dos outros, não simplesmente para que eles façam o que se quer, mas para que operem como se quer", segundo a rapidez e a eficácia determinada pela técnica. (SANT'ANNA; PERSON, 2020, p. 85).

Esse filme de Farocki figura a distopia não apenas porque evidencia, por meio de imagens de arquivos, a estrutura disciplinar e de controle existente nos presídios, mas também porque alerta, por meio dessas imagens, para o fato de que a vigilância incessante também está presente, ainda que em graus diversos, em outras esferas da vida social, seja para proteger a propriedade privada, seja para coibir protestos nas ruas, seja para treinar pessoal nas empresas. É o que ocorre, nesse último caso, no vídeo Os criadores dos impérios das compras (Die Schoöpfer der Einkaufswelten), de 2001, no qual Farocki, utilizando-se de gravações operacionais de reuniões de gerentes de vendas e de palestras de marketing destinadas à "formação de pessoal", lança luz sobre as estratégias habituais empregadas em shoppings centers, no intuito de controlar o olhar dos consumidores desde sua entrada no edifício, a fim de maximizar as vendas.

As obras de Harun Farocki efetuam, portanto, uma crítica à sociedade de controle haja vista que elas restituem ao público as imagens esquecidas, censuradas, ou simplesmente mantidas em domínio privado. Seus filmes, que são montagens de imagens recolhidas de arquivos visuais até então mantidos em sigilo, como vimos, desvelam as estratégias de poder das instituições públicas e das empresas privadas. Farocki apropria-se destas gravações para, após detido trabalho de seleção e montagem, devolvê-las aos seus verdadeiros titulares, alertando para o fato de que essas imagens constituem nosso "bem comum". Devolvê-las à comunidade significa tornar público que, como essas imagens de poder nos concernem, elas devem integrar nosso "patrimônio visual coletivo." (DIDIHUBERMAN, p. 212). 
Farocki, em outros termos, salva as imagens do esquecimento; ele as emancipa, ao conceder-lhes uma sobrevida. Esse processo de restituição das imagens funcionais ou de "uso técnico", ao "livre uso dos homens", Giorgio Agamben denomina "profanação": "Por isso é importante toda vez arrancar dos dispositivos - de todo dispositivo - a possibilidade de uso que os mesmos capturaram. A profanação do improfanável é a tarefa política da geração que vem." (AGAMBEN, 2007, p. 79). Na profanação que visa à transparência de uma sociedade livre, em oposição à obscuridade de uma sociedade de controle, toda a autoria, inclusive a do artista, é desautorizada. Farocki é, por isso, um arqueólogo que interroga "o subterrâneo da história das imagens" - como já assinalou Didi-Huberman (2015, p. 222-3) - sem afirmar um estilo pessoal, ou seja, sem ser tomado pelo "páthos apocalíptico". Em seus filmes, ao contrário, apesar da montagem das imagens, a autoria é substituída por uma "voz neutra", em terceira pessoa, "impessoal", um sujeito de enunciação coletiva, enfim: "Tal foi o preço artístico a pagar" para que as imagens de um mundo distópico, como o das prisões e das empresas, fossem restituídas, não como "lugares-comuns" (ou clichês), "mas como o lugar do comum." (DIDI-HUBERMAN, 2015, p. 223).

O artista (e ativista) Ai Weiwei realiza uma crítica sistemática ao governo chinês. Desde seu regresso à China, em 1993, após ter residido por uma década em Nova York, Ai Weiwei mostra que a destruição (Chai-na) é uma política

${ }^{2}$ Ai Weiwei indica como referências decisivas em seu processo de formação - no período em que viveu na comunidade artística chinesa em Nova York, de 1981 a 1993, antes, portanto, de regressar à China - Marcel Duchamp e Andy Warhol: "Acho que [como nesses artistas] a minha posição e o meu modo de vida são a minha arte mais importante" (AI WEIWEI apud STAHEL, 2013, p. 38, grifo nosso). de Estado na China. ${ }^{2}$ Com objetos, instalações, vídeos ou performances, ele evidencia o caráter opressivo vivido no país desde que o Partido Comunista Chinês, dirigido por Mao Tse-Tung, fundou, em 1949, a República Popular da China. Sua denúncia ao caráter autocrático do Estado chinês abarca tanto o período da Grande Revolução Cultural Proletária, de 1966 a 1976, que introduziu o comunismo - removendo, simultaneamente, os traços capitalistas (como a dita ideologia burguesa) e os valores mais tradicionais da sociedade chinesa -, quanto o período da reforma estrutural da economia promovida a partir de 1978 por Deng Xiaoping que abriu a China para a economia de mercado. Se, por um lado, o crescimento econômico da China, desde então, é admirável, comparativamente aos índices dos países ocidentais, por outro lado, seu regime político é condenável, uma vez que ele é uma 
"ditadura" do Partido Comunista chinês. São os mecanismos de controle da vida social, política e cultural do governo chinês que são denunciados por Ai Weiwei, há três décadas. Se seu pai Ai Qing, importante poeta chinês, foi enviado para um campo de trabalhos forçados na época da Revolução Cultural, Ai Weiwei, por sua vez, foi preso em local secreto em 2011, por oitenta e um dias; e, de 2013 a 2015, foi impedido de viajar ao exterior, além de ter seus ateliês em Pequim destruídos pela polícia política chinesa, em 2011 e 2018.

No centro da poética de resistência de Ai Weiwei, está a denúncia à destruição da arte e da arquitetura tradicionais, e, portanto, dos antigos modos de vida na China. Na instalação Reto, construída de 2008 a 2012, Ai Weiwei reporta-se a uma tragédia ocorrida em 12 de maio de 2008. Nesse dia, um terremoto de grande magnitude devastou a província chinesa de Sichuan provocando a morte de 10 mil pessoas, entre as quais 5 mil estudantes que morreram soterrados nas escolas construídas de modo precário pelo governo chinês. Esses desabamentos das escolas mal construídas, que foram vistos pela população da região como consequência da corrupção do governo local - uma vez que outras edificações não ruíram -, nunca foram investigados plenamente pelo governo que sequer informou com precisão o número e os nomes dos estudantes vitimados na tragédia. Reagindo a essa omissão do governo chinês, Ai Weiwei, mobilizando centenas de moradores da região de Sichuan, criou a comitiva "Investigação dos cidadãos", visando à apuração do real estado dos edifícios no momento do terremoto; do número preciso de vítimas deste desastre, assim como do nome de cada uma delas.

O resultado dessa investigação, que se estendeu de 2008 a 2011, foi exposto em várias galerias e museus do Ocidente, na forma de um amplo painel com a identificação dos 5.196 estudantes mortos, a idade, turma e região de origem de cada um deles; além de exibir relatórios técnicos sobre as condições materiais das 153 escolas destruídas. Na versão de 2015 dessa instalação, Weiwei exibiu, ainda, junto a esses painéis, 164 toneladas de vergalhões de aço - devidamente desentortados, ao longo de um ano - extraídos dos escombros dessas escolas. Dispostos no chão, como monumento minimalista, Reto é um memorial que, lidando com o trauma social, elabora a perda de vidas, trabalhando coletivamente o luto. Rememorando os 
estudantes mortos, os vergalhões endireitados impedem que se apague a responsabilidade do poder público pela tragédia, ou, em outros termos, revela o caráter de "necropolítica" do governo chinês uma vez que este determina direta ou indiretamente - a julgar pelo resultado da "Investigação dos cidadãos" - "como algumas pessoas devem viver e como outras podem morrer" (MBEMBE, 2017, p. 37). Pode-se tomar assim a correção dos vergalhões pela comunidade de ferreiros contratados pelo artista, como um alerta para o risco de a sociedade recalcar o ocorrido, perdoando o governo pelo poder de ditar a vida e a morte dos governados.

A China distópica de Ai Weiwei é a da extinção do passado cultural. Na Documenta 12 de Kassel, em 2007, o artista concebeu para um parque da cidade a instalação Template: um conjunto escultórico, de grandes proporções, construído com "diversas portas e caixilhos de janelas de edifícios destruídos da época das Dinastias Ming (1368-1644) e Qing (1644-1912)", com uma abertura na forma de pórtico de templo (TANCOCK, 2018, p. 49). Em 2016, Ai Weiwei fotografou-se no instante (decisivo) em que "deixava cair" uma urna da Dinastia Han (206 a.C.-220 d.C.), alertando para a destruição de relíquias tradicionais das diferentes etnias e culturas da China. Essa fotografia da urna em plena queda, que foi incorporada ao acervo de museus ocidentais, tornou-se um emblema da poética de risco do artista.

Defensor dos direitos humanos, Ai Weiwei reagiu também ao cerceamento da livre expressão num país caracterizado pelo dirigismo cultural. Basta lembrar que foi apenas a partir dos anos 1990 que a arte contemporânea do Ocidente, das décadas anteriores, como a pop arte e a arte conceitual, tornou-se conhecida na China. Para subtrair-se à censura estatal que o impedia até mesmo de expor no país, Ai Weiwei dedicou-se ao ativismo na web criando um blog de fotos e depoimentos, de 2005 a 2009, e, mais recentemente, um microblog no Twitter. Ai Weiwei (2013) passou então com seus posts no Twitter a operar como "rede, como empresa", enquanto "voz política", como caixa de ressonância social, ou agent provocateur. Pelo exame de seus posts (que posteriormente foram apagados da internet chinesa pelo governo), pode-se advogar que não há em $\mathrm{Ai}$ Weiwei nem mera comunicação, nem culto à personalidade do artista no sentido da fetichização da autoria uma vez que sua posição equivaleria a de um "coletivo de enunciação", o que 
significa dizer que sua voz seria o meio pelo qual se instauraria o "dissenso" (a "polifonia do anônimo"), entendidos como "o conflito sobre a constituição mesma do mundo comum" (no caso, a sociedade chinesa em sua relação com o Ocidente), nos termos de Jacques Rancière (1996, p. 374). Foi essa cruzada digital pelos direitos humanos que denunciava o autoritarismo do governo chinês que o levou à prisão, em 2008, e ao exílio no Ocidente, de 2015 a 2019, na Alemanha, e, desde então, na Inglaterra.

O artista espanhol Antoni Muntadas também figura, desde os anos 1980, sociedades distópicas. Seu objetivo é mostrar como as estruturas de poder sempre atuaram, por meio de uma arquitetura monumental, no espaço público. No interior do espaço protegido das galerias e dos museus, Muntadas evidencia, em videoinstalações (ou media architecture installations, na expressão da crítica de arte) a existência desde o mundo antigo de uma arquitetura destinada aos espetáculos de massa, tais como os anfiteatros, termas, circos, estádios ou igrejas. Suas obras audiovisuais que recorrem aos arquivos de imagens ou bancos da memória investigam os lugares nas metrópoles que acolheram eventos esportivos, políticos, religiosos ou de mero entretenimento, bem como - no caso dos espetáculos contemporâneos - sua repercussão pelas mídias de massa e pela rede digital no dito mundo global.

Seu intento é questionar, por meio de uma genealogia de imagens - do Coliseu em Roma, de 80 d.C., ao Estádio Nacional de Pequim (ou Ninho de pássaro, de Herzog e de Meuron, Arup e Ai Weiwer de 2008) o poder da arquitetura monumental de instrumentalizar politicamente as manifestações de massa. A projeção dessas imagens, em suas videoinstalações, mostra não apenas que o poder político sempre encontrou, ao longo da história, na arquitetura edificada, um dispositivo de dominação; mas, também, que esse mesmo poder é exercido, na contemporaneidade, pelo dispositivo da midiatização dos eventos (ou seja, pela sua conversão em imagens que produzem fascínio no observador) que ocorrem nessas arenas.

O objetivo de Muntadas, dito de outro modo, é mostrar a face funesta da festa, que tem como paradigma o panem et circensis romano. Na instalação Stadium XII de 2006 que integra uma série iniciada em 1989 -, o artista dispôs circularmente colunas de material pré-fabricado que remetem 
à arquitetura clássica ou neoclássica, de modo a circunscrever uma arena. Essas colunas robustas, porque de amplo diâmetro, que não ocultam sua dimensão de artifício ou simulacro, por estarem muito próximas umas das outras (afinal, apenas $40 \mathrm{~cm}$ as separam), operam como obstáculos, impedindo a passagem do público. No centro dessa arena demarcada pela colunata, que não pode ser transposta pelo visitante, o artista instalou projetores que lançam ininterruptamente imagens de tipologias arquitetônicas de estádios, nas divisórias, também circulares, posicionadas atrás das colunas. Dessa maneira, o observador se vê "sitiado", não apenas porque não pode ingressar na arena para assim adquirir algum protagonismo, mas também porque acaba reduzido à condição de mero voyeur, uma vez que ele apenas entrevê, pelos vãos das colunas, as imagens projetadas nas divisórias.

Essa disposição das colunas e dos projetores tem por finalidade incitar o observador a habitar criticamente o espaço da instalação. Se o caráter cenográfico dessas colunas neoclássicas toscas remete à arquitetura monumental nazifascista, como as de Albert Speer ou Marcello Piacentini, os projetores situados no centro do círculo evocam, por sua vez, a torre de vigilância central dos presídios estadunidenses do século $X X$, que se basearam na Planta de panopticon de Jeremy Bentham, de 1785. Stadium XII pode ser percebido, portanto, como um panóptico circense pós-moderno, ou seja, como o lugar de uma triste liturgia de consumo passivo de imagens-clichês por parte de uma audiência habituada ao entretenimento. A experiência de submissão resulta não apenas do confinamento espacial ao qual o visitante se vê relegado, mas também da vulnerabilidade na qual ele se encontra em face das projeções ininterruptas de "imagens sonoras" estridentes, como aplausos, gritos, jingles, hinos, slogans ou fogos de artifícios.

Essas imagens sonoras em looping que alvejam o corpo sensório-motor do observador visam - na intenção de Muntadas - a fazê-lo refletir sobre o esvaziamento de sentido de uma experiência coletiva (que acaba reduzido a uma imagem espectral), e, por conseguinte, dos agenciamentos políticos e econômicos daí decorrentes. Da posição de voyeur que lhe foi determinada, o observador seria levado, então, a indagar: é possível "situar-se no fora de um mundo que disseminou as técnicas de poder" que antes atuavam em um 
espaço arquitetônico determinado, mas que, com o advento das imagens midiáticas (inicialmente com os mass-media, como o rádio e a televisão, e, desde os anos 1990, com as redes digitais), se estenderam no espaço e no tempo, vindo assim a ocupar todos os lugares: a casa, o local de trabalho e o próprio deslocamento pela cidade, com os smartphones? (GARCIA, 2007, p. 118).

Stadium XII é, em suma, uma ambiência distópica na medida em que produz uma experiência de desrealização do real (de apagamento da prática coletiva de participação nas arenas monumentais, ainda que esta também, como vimos, seja uma forma de sujeição): nela, a evocação do passado converte-se, em aparente paradoxo, em amnésia histórica; ou ainda: o "arquétipo do stadium" - na expressão de Muntadas (GARCIA, 2007, p. 127) - é vertido em imagem-clichê, em signos intensíssimos do ponto de vista sensorial, mas vazios ou descarnados (sem lastro no "real"), porque dissociados da experiência histórica e da memória coletiva.

Diversos críticos, para caracterizar a criação de outros espaços nas artes visuais, têm recorrido não apenas à noção de distopia (como fizemos a propósito das obras de Harun Farocki, Ai Weiwei e Antoni Muntadas), mas também à noção de heterotopia, no termo empregado por Michel Foucault (2001, p. 415) em conferências nos anos 1960. As utopias foram caracterizadas, nessas ocasiões, pelo autor, como "posicionamentos sem lugar real", como "espaços essencialmente irreais", seja "a própria sociedade aperfeiçoada" (como a Cidade Radiosa enquanto síntese das artes do projeto moderno, como vimos), ou "o inverso desta sociedade" (as distopias). As heterotopias, por sua vez, seriam "contraposicionamentos em lugares reais", "lugares efetivos" - ou seja, "lugares" que, em aparente contradição, "estão fora de todos os lugares, embora sejam efetivamente localizáveis." (FOUCAULT, 2001, p. 415).

Findo o projeto moderno, o desafio de muitos artistas, segundo os críticos de arte que têm mobilizado essa noção de Foucault, não é mais imaginar utopias ou distolpias, mas habitar de outro modo, ainda que apenas por certo tempo, a realidade existente. Para tanto, esses artistas teriam criado espaços laboratoriais, de gestação de novas modalidades de se viver junto. Seriam “outros lugares", porque não são a família, 
o partido político, o sindicato, a escola, a empresa, a igreja etc. As enumerações vivas de heterotopias apresentadas por Foucault, movidas pelo calor da oralidade de suas conferências, surpreendem o leitor por sua diversidade. Daniel Defert (2013, p. 35) assinala, por exemplo, que em conferência radiofônica, em 1966, Foucault apresentou como "a primeira heterotopia, a cama dos pais, que as crianças gostam de invadir com um prazer de transgressão e de sonhos das origens". É importante salientar que sua intenção não era prescrever, empiricamente, as heterotopias, mas ajudar a figurá-las, a imaginar "ambiências heterotópicas" que evidenciassem "a existência de espaços singulares" que encontramos no interior dos "espaços sociais já existentes", "inaugurando, assim [nos termos de Defert (2013, p. 43-44)], um campo para a interpretação qualitativa dos espaços outros", em sintonia com as pesquisas artísticas já em curso nos anos 1960.

As heterotopias são espaços de resistência: "lugares que a sociedade dispõe em suas margens, nas paragens vazias que as rodeiam", "aos indivíduos cujo comportamento é desviante relativamente à média ou à norma exigida." (FOUCAULT, 2013, p.22). Foucault (2001, p. 420) menciona, como outro exemplo de heterotopia, os "famosos quartos que existiam nas grandes fazendas do Brasil, e, em geral, da América do Sul", nos quais "a porta para neles entrar dava para o cômodo central em que vivia a família", de tal modo que "todo o indivíduo que por lá passasse - todo o viajante que "não era um convidado, mas um hóspede de passagem" - "tinha o direito de empurrar essa porta, de entrar no quarto e de dormir ali uma noite", sem "jamais alcançar o próprio núcleo da família". Seria um espaço de transição situado entre o espaço público e o espaço privado para descansar e viver bem antes de prosseguir na viagem. Foucault destaca, ainda, como exemplos, os "bordéis e as colônias", e, sobretudo, o navio - ao qual se refere nas duas conferências sobre o tema - como "a maior reserva de imaginação":

O navio é a heterotopia por excelência. Civilizações sem barco são como crianças cujos pais não tivessem uma grande cama na qual pudessem brincar; seus sonhos então se desvanecem, a espionagem substitui a aventura, e a truculência dos policiais, a beleza ensolarada dos corsários. (FOUCAULT, 2001, p. 422). 
Diferentemente do projeto moderno na arquitetura que concebeu o espaço como abstrato e seus habitantes como usuários genéricos no espaço público - demonstrando, assim, seu vínculo congênito com o próprio processo econômico e social calcado na lógica igualmente abstrata de valor de troca -, "as heterotopias não refletiriam a estrutura social nem a da produção", na medida em que não estariam orientadas por "um sistema sócio-histórico", ou por "uma ideologia" determinada, mas pela ideia de ruptura [ou suspensão], ainda que temporária, com "a vida ordinária", que liberaria "imaginários, representações polifônicas da vida, da morte, do amor, de Éros, e Thánatos." (FOUCAULT, 2013, p. 52, grifo nosso).

Pode-se acrescentar aos exemplos de Foucault certa produção artística, dos mesmos anos 1960, que intentava criar "outros espaços". Nesses anos, vale lembrar que o artista Hélio Oiticica se referia ao crelazer, e Lygia Clark ao relax. A ideia de crelazer de Oiticica "começa a tomar corpo em 1967" com a Cama Bólide (a "cama dos pais" como quer Foucault?): "uma cabine onde as pessoas se deitam, experimentam sensações e recobram modos de viver, de estar no mundo." (FAVARETTO, 1992, p. 185). O crelazer não é "lazer repressivo", "dessublimatório, mas o lazer usado como ativante não repressivo", resultado da "catalisação das energias não-opressivas" de dada ambiência. (OITICICA, 1986, p. 117). É "lazer criador", ou seja, um "estado de pura disponibilidade"; "um lazer-prazer-fazer" "que assimila a atividade criativa ao devir das vivências" dos participantes. (FAVARETTO, 1992, p. 150).

De modo semelhante, Lygia Clark distinguia, nesses mesmos anos, o "relax" do descanso usufruído em horas de lazer, uma vez satisfeitas as "necessidades reais" do trabalho, porque, diferentemente dessas, a ociosidade seria, nos termos da artista, "uma experiência aliciante de transformação do nosso sentido mais profundo do eu, do outro e do ambiente." (CLARK, 1996, p. 150). Suas "proposições construtivas", que visavam à simplicidade de um lazer vital calcado na desaceleração do desempenho e da produtividade, contrapunham-se à "dessublimação repressiva" do lazer administrado, permitindo que o participante vivesse seu otium cum dignitate numa era na qual - na referência de Oswald de Andrade (1978, p. 176) a Aristóteles - os "fusos trabalhavam sozinhos". A liberdade, 
para Clark, leitora de Herbert Marcuse (1982), não seria, assim, desocupação, mas atividade livre. A distensão contínua nesse espaço micrológico resultaria, no imaginário da artista, da "tendência a manter constante" a "quantidade de excitação" experimentada durante a vivência construtiva, porque o predomínio da compulsão à repetição, requerida pela memória de um corpo gratificado pela experiência, poderia converter toda percepção futura em possível fonte de prazer, ou ao menos dissociar os atos do cotidiano do "desprazer neurótico" e as relações pessoais do "desdém narcisista." (FREUD, 2010, p. 161-239).

Essa tentativa de "inventar novas relações com o mundo existente" ao invés de imaginar utopicamente "um novo mundo fundado em novas relações" é visível também na dita "arte relacional", a partir dos anos 1990, na expressão de Nicolas Bourriaud (2009, p. 123). Na $27^{\text {a }}$ Bienal de São Paulo, em 2006, o argentino Rirkrit Tiravanija expôs a obra Palm pavilion atualmente exibida no Instituto Inhotim, em Brumadinho, Minas Gerais -, que é uma versão das Maisons tropicales de Jean Prouvé. Cabe reavivar que, entre 1959 e 1961, o arquiteto Jean Prouvé, na esteira de Le Corbusier, concebeu modelos de casas pré-fabricadas, atendendo a uma encomenda do governo francês para suas colônias na África. Essas construções - Les Maisons tropicales - visavam a suprir a falta de infraestrutura em habitação no Congo para diplomatas franceses. Eram protótipos de casas leves, com estruturas em aço, portas corrediças em seu interior, e um sistema de ventilação que seria adequado ao clima africano. Seus diferentes módulos seriam fabricados e montados nas indústrias francesas antes de serem enviadas, por avião de carga, às colônias africanas.

Em Palm pavillion, Tiravanija reconstrói esse modelo de casa funcional de Jean Prouvé, mas com materiais precários, abrigando em seu interior diferentes espécies de palmeiras urbanas, uma vitrine com plantas - com um quebra-cabeça -, além de uma série de vídeos. Em um desses vídeos, há um documentário sobre um teste nuclear no Pacífico Sul calcinando um grupo de palmeiras; em outro vídeo, temos uma sequência de imagens que apresenta as palmeiras ora como referência sociocultural, ora como taxonomia científica, e, por fim, como efígie em dólar e selo. Nessa recriação no Brasil de uma casa emblemática da arquitetura modernista suíço-francesa, 
Tiravanija problematiza os "sistemas de coexistência" - na expressão do próprio artista -, ou seja, as trocas culturais que foram recalcadas pela "Ideologia do Plano Moderno", marcadamente neocolonialista (BOURRIAUD, 2009a, p.5155). O Palm pavilion, cercado, hoje, por 130 palmeiras de sete espécies, de diferentes procedências e tamanhos - destacandose que a palmeira, convertida em ícone do exotismo tropical não é planta nativa brasileira - cria um habitat em torno dos vídeos e plantas, evidenciando que tanto as plantas quanto os materiais e as formas arquitetônicos possuem uma história de migrações, deslocamentos ou nomadismo. Contra a Utopia da Ordem, Tiravanija instaura, assim, "a desordem que faz cintilar os fragmentos de um grande número de ordens possíveis." (FOUCAULT, 2013, p. 35).

Em síntese: como o futuro não é mais percebido como "promissor", ou seja, como "fonte de esperança, expansão e crescimento" - como afirma Franco Berardi (2019, p.135), em Depois do futuro, retomando Octavio Paz (1984) - mas, sim, como "amedrontador", houve um deslocamento no imaginário artístico das utopias (Cidade Ideal) tanto para as distopias (como as sociedades de controle figuradas nas obras de Harun Farocki, Ai Weiwei e Antoni Muntadas), quanto para as heterotopias que visam à inscrição de outros espaços no cotidiano vivido, como ocorre em Rirkrit Tiravanija (ou, mais remotamente, em Lygia Clark, e Hélio Oiticica). São as duas formas pelas quais a arte contemporânea manifesta seu poder de negatividade, ainda que se admita que "a catástrofe é o horizonte insuperável do nosso tempo", ou seja, que vivemos "à sombra da iminência da destruição planetária, a hora histórica em que passamos a viver não mais uma época, mas um prazo, o tempo que resta." (ARANTES, 2014, p. 39). Neste caso, "o tempo que resta" será o da resistência, a julgar pelas obras vistas, até porque como, dizia Adorno (1998, p. 185), “os protestos sem esperança são necessários." 


\section{REFERÊNCIAS}

ADORNO, Theodor. Prismas: crítica cultural e sociedade. São Paulo: Ática, 1998.

ADORNO, Theodor; HORKHEIMER, Max. Dialética do esclarecimento. Rio de Janeiro: Jorge Zahar, 1985.

ANDRADE, Oswald. Do Pau-Brasil à Antropofagia e às Utopias: manifestos, teses de concursos e ensaios - Obras Completas VI. Rio de Janeiro: Civilização Brasileira, 1978.

ARANTES, Paulo. O novo tempo do mundo. São Paulo: Boitempo, 2014.

AI WEIWEI. O blogue de Ai Weiwei: escritos, entrevistas e arengas digitais, 2006-2009. Organização de Lee Ambrozy. São Paulo: Martins Fontes, 2013.

AGAMBEN, Giorgio. Profanações. São Paulo: Boitempo, 2007.

BAUDRILLARD, Jean. Simulacros e simulação. Lisboa: Relógio d'Água, 1991.

BERARDI, Franco. Depois do Futuro. São Paulo: Ubu Editora, 2019.

BOURRIAUD, Nicolas. Estética relacional. São Paulo: Martins: 2009.

. Pós-produção: como a arte reprograma o mundo contemporâneo. São Paulo: Martins: 2009a

CLARK, Lygia. Lygia Clark, Hélio Oiticica: Cartas 1964-74. Organização de Luciano Figueiredo. Rio de Janeiro: Ed. da UFRJ, 1996.

DEBORD, Guy. Crítica ao urbanismo. IS, n. 6, ago. 1961. In: BERENSTEIN, Jacques P. (org.). Apologia da deriva: escritos situacionistas sobre a cidade. Rio de Janeiro: Casa da Palavra, 2003. p. 132-138. 
DEFERT, Daniel. Heterotopia: Tribulações de um conceito entre Veneza, Berlim e Los Angeles. In: FOUCAULT, Michel. O corpo utópico, as heterotopias. São Paulo: n-1 edições, 2013. p. 33-55.

DELEUZE, Gilles. Conversações, 1972-1990. Rio de Janeiro: Ed. 34, 1992.

DIDI-HUBERMAN, Georges. Sobrevivência dos vaga-lumes. Belo Horizonte: Ed. da UFMG, 2011.

Devolver uma imagem. In: ALLOA, Emmanuel (org.). Pensar a imagem. Belo Horizonte: Autêntica Editora, 2015, p. 205-225.

FAVARETTO, Celso F. A invenção de Hélio Oiticica. São Paulo: Edusp, 1992.

FOUCAULT, Michel. Outros espaços. In: Ditos e escritos III. Estética: literatura e pintura, música e cinema. Rio de Janeiro: Forense Universitária, 2001.

2013.

O corpo utópico, as heterotopias. São Paulo: n-1 edições,

FREUD, Sigmund. História de uma neurose infantil; O homem dos lobos; Além do princípio do prazer e outros textos (1917-1920). São Paulo: Companhia das Letras, 2010.

GARCIA, Illiana H. Stadium: Habitabilidad de um panopticon circenses. In: BUCELLATO, Laura (org.). Atencion: la percepcion requiere participacion: MUNTADAS/ BS. AS. Buenos Aires: Espacio Fundación Telefónica, 2007. p. 108-119.

HORKHEIMER, Max. Eclipse da razão. Rio de Janeiro: Editorial Labor do Brasil, 1976.

LE CORBUSIER (Charles-Edouard Jeanneret-Gris). Os três estabelecimentos humanos. São Paulo: Perspectiva, 1976. . Por uma arquitetura. São Paulo: Perspectiva, 1981. A carta de Atenas. São Paulo: Editora Hucitec/Edusp, 1989. 
JACQUES, Paola B. (org.). Apologia da deriva: Escritos situacionistas sobre a cidade. Rio de Janeiro: Casa da Palavra, 2003.

MALIÉVITCH, Kasimir. El Nuevo Realismo Plastico. Madrid: Alberto Corazon, 1975.

MARCUSE, Herbert. A dimensão estética. Lisboa: Ed. 70, 1986. A ideologia da sociedade industrial: o homem unidimensional. Rio de Janeiro: Zahar Editores, 1982.

MBEMBE, Joseph-Achille. Necropolitica. São Paulo: n-1 edições, 2018.

MONDRIAN, Piet. Neoplasticismo na pintura e na arquitetura. São Paulo: Cosac; Naify, 2008.

OITICICA, Hélio. Aspiro ao Grande Labirinto. Rio de Janeiro: Rocco, 1986.

PAZ, Octavio. Tempo nublado. Rio de Janeiro: Guanabara, 1986. Os filhos do barro. Rio de Janeiro: Nova Fronteira, 1984.

PLATÃO. A República. Lisboa: Fundação Calouste Gulbenkian, 1983.

RANCIÈRE, Jacques. O dissenso. In NOVAES, Adauto (org.). A Crise da razão. São Paulo: Companhia das Letras; 1996, p. 367-382.

SANT'ANNA, Antonio Carlos.; PERSON, Flávia. Humanidade e crítica de Harun Farocki: uma análise dos temas recorrentes na montagem do documentário Imagens da prisão. $A R S$, São Paulo, v. 18, n. 38, p. 79-106, 2020.

SCHILLER, Friedrich. A educação estética do homem: numa série de cartas. São Paulo: Iluminuras, 1990.

STAHEL, Urs. (org.). Ai Weiwei: interlacing. São Paulo: Museu da Imagem e do Som, 2013. 
TANCOCK, John L. Radical de nascimento. In: DANTAS, Marcelo (org.). Raiz Weiwei. São Paulo: Ubu Editora, 2018. p. 17-110.

\section{Abstract \\ Other Spaces in the Visual Arts}

The article initially characterizes the concept of temporality that prevailed in the imaginary of the artistic avant-gardes of the years 1910 to the years 1930: the idea of a linear time, successive, cumulative, homogeneous and "empty", because to be conquered. It was this conception of prospective time, teleological, in which the télos is the Utopia, which guided the constructive vanguards until the Second World War. After the Holocaust (or the bombs of Hiroshima and Nagasaki), the ideas of progress, or improvement, proper to this prospective conception of time, collapsed. The future is nolonger considered the realm of hope, of the projection of desire, to become dark or threatening. Since then, the notion of dystopia, or negative utopia, has prevailed in the artistic-cultural imaginary, understood as the figuration of an oppressive society projected in the near or distant future, applies to the artisticcultural imaginary, which will be reached if the course of history is not changed. This is what we see in the visual works of the German artist Harun Farocki, the Chinese Ai Weiwei and the Spanish Antoni Muntadas, carried out over the last three decades, in which dystopia is presented as a control society. Finally, we believe that several art critics have been mobilizing, since the 
1990s, the notion of Michel Foucault's heterotopia to characterize the power of negativity of certain contemporary art. We recall that heterotopias are, for the author, "contrapositions in real places", "effective places"; that is, "places" that is, "places" that, in apparent paradox, "are out of all places, although they are effectively localizable", as would occur, in our view, in artistic installations of Rirkrit Tiravanija (or, more remotely, to Lygia Clark and Helio Oiticica).

Keywords: Contemporary Art.

Utopia. Dystopia. Heterotopia. Resistance.

Ricardo Nascimento Fabbrini é Doutor em Filosofia pela USP. É professor livre-docente de estética do Departamento de Filosofia da Faculdade de Filosofia, Letras e Ciências Humanas da Universidade de São Paulo (FFLCH-USP) e do Programa de Pós-Graduação Interunidades em Estética e História da Arte da mesma Universidade. (PGEHAUSP). É membro do Conselho Deliberativo do Museu de Arte Contemporânea da USP (MAC-USP) e coordena do Grupo de Estudos em Estética Contemporânea da USP. Desenvolve pesquisas nas áreas de estética, filosofia da arte, arte contemporânea, arte moderna e arte brasileira. 